\title{
Effects of $\mathrm{SiO}_{2}$ Incorporation on the Flexural Properties of a Denture Base Resin: An In Vitro Study
}

\author{
${ }^{1}$ Department of Dental Education, College of Dentistry, Imam \\ Abdulrahman Bin Faisal University, Dammam, Saudi Arabia \\ ${ }^{2}$ Department of Dental Education, College of Dentistry, Imam \\ Abdulrahman Bin Faisal University, Dammam, Saudi Arabia \\ ${ }^{3}$ Department of Biophysics, Institute for Research and Medical \\ Consultations, Imam Abdulrahman Bin Faisal University, Dammam, \\ Saudi Arabia \\ ${ }^{4}$ Biomedical Engineering department, College of Engineering, Imam \\ Abdulrahman Bin Faisal University, Dammam, Saudi Arabia \\ ${ }^{5}$ Department of Substitutive Dental Sciences, College of Dentistry, \\ Imam Abdulrahman Bin Faisal University, Dammam, Saudi Arabia
}

Sara T. Alzayyat ${ }^{1}$ Ghadah A. Almutiri ${ }^{1}$ Jawhara K. Aljandan ${ }^{1}$ Raneem M. Algarzai

Soban Q. Khan ${ }^{2}$ Sultan Akhtar ${ }^{3}$ ljlal Shahrukh Ateeq ${ }^{4}$ Mohammed M. Gad ${ }^{5}$

Address for correspondence Sara T. Alzayyat, BDS, College of Dentistry, Imam Abdulrahman Bin Faisal University, P.O. Box 1982, Dammam 31411, Saudi Arabia (e-mail: sara.t.alzayyat@gmail.com).

\author{
Abstract

\section{Keywords} \\ - denture base \\ - elastic modulus \\ - flexural strength \\ - polymethyl \\ methacrylate \\ - silicon dioxide \\ nanoparticles
}

Objective The aim of this study was to evaluate the effects of the addition of low-silicon dioxide nanoparticles (nano-SiO ${ }_{2}$ ) on the flexural strength and elastic modulus of polymethyl methacrylate (PMMA) denture base material.

Materials and Methods A total of 50 rectangular acrylic specimens $(65 \times 10 \times$ $2.5 \mathrm{~mm}^{3}$ ) were fabricated from heat-polymerized acrylic resin. In accordance with the amount of nano-SiO ${ }_{2}$, specimens were divided into the following five groups ( $n=10$ per group): a control group with no added $\mathrm{SiO}_{2}$, and four test groups modified with 0.05 , $0.25,0.5$, and $1.0 \mathrm{wt} \%$ nano-SiO${ }_{2}$ of acrylic powder. Flexural strength and elastic modulus were measured by using a 3-point bending test with a universal testing machine. A scanning electron microscope was used for fracture surface analyses. Data analyses were conducted through analysis of variance and Tukey's post hoc test $(\alpha=0.05)$.

Results Compared with the control group, flexural strength and modulus of elasticity tended to significantly increase $(p<0.001)$ with the incorporation of nano-SiO${ }_{2}$. In between the reinforced groups, the flexural strength significantly decreased $(p<$ 0.001 ) as the concentrations increased from 0.25 to $1.0 \%$, with the $1.0 \%$ group showing the lowest value. Furthermore, the elastic modulus significantly increased ( $p<$ 0.001 ) at $0.05 \%$ followed by $1.0 \%, 0.25 \%, 0.5 \%$, and least in control group.

Conclusion A low nano-SiO ${ }_{2}$ addition increased the flexural strength and elastic modulus of a PMMA denture base resin. published online

August 24, 2021
DOI https://doi.org/

$10.1055 / \mathrm{s}-0041-1732806$ ISSN 1305-7456
(C) 2021. The Author(s).

This is an open access article published by Thieme under the terms of the Creative Commons Attribution License, permitting unrestricted use, distribution, and reproduction so long as the original work is properly cited. (https:// creativecommons. org/licenses/by/4.0/).

Thieme Medical and Scientific Publishers Pvt. Ltd. A-12, 2nd Floor, Sector 2, Noida-201301 UP, India 


\section{Introduction}

Polymethyl methacrylate (PMMA) denture base has been the most commonly used material for removable prostheses since 1930. The popularity of PMMA is based on its various advantages, which include being light weight, inexpensive, biocompatible, and having good esthetics. ${ }^{1}$ However, it has poor mechanical properties, which are considered the main cause of denture fractures. ${ }^{2}$ To overcome this drawback, many attempts to improve the properties of denture base resins have been attempted through chemical modifications or changes to the polymerization cycle to produce high-impact resins with greater strength. ${ }^{3,4}$ Another way to enhance the physical properties of PMMA is to include various additives and reinforcement materials by incorporating wires, fibers, and metallic oxides. ${ }^{5,6}$ In addition, nanoparticles have been added to PMMA to improve its mechanical properties, including compressive and flexural strength. ${ }^{7}$ For example, adding silicon dioxide nanoparticle (nano-SiO ${ }_{2}$ ) to PMMA enhances thermal and physical properties due to their high surface activity, strong interfacial interaction with organic polymers, and large specific surface areas.,8-10

Many studies have investigated that the addition of nano- $\mathrm{SiO}_{2}$ to PMMA and have recommended using low-concentration additions. ${ }^{911-13}$ According to Cevik and Yildirim-Bicer, the addition of nano-SiO ${ }_{2}$ in high concentrations (ratios: 1.0 and 5\%) to PMMA decrease its mechanical properties. ${ }^{11}$ Sodagar et al also incorporated nano- $\mathrm{SiO}_{2}$ at 1.0 and $0.5 \%$ into PMMA for removable appliances and found a decrease in flexural strength. Moreover, this reduction was directly related to the concentration of nano- $\mathrm{SiO}_{2} \cdot{ }^{9} \mathrm{Gad}$ et al and Abushowmi et al also added nano- $\mathrm{SiO}_{2}(0.25,0.5$, and $0.75 \%$ ) to the PMMA repair resin and found that the highest increase in flexural strength is observed with $0.25 \%$ compared with the higher concentrations. ${ }^{12,13}$ Therefore, lower concentrations of nano- $\mathrm{SiO}_{2}$ into PMMA to assess mechanical properties have been recommended for further investigations. A recent study by Alzayyat et al found that the addition of low concentrations of nano-SiO ${ }_{2}(0.05,0.25,0.5$, and $1.0 \%$ ) to PMMA denture base resin has positive effects on Candida albicans adhesion, hardness, and contact angle, while translucency and surface roughness are adversely affected at higher concentrations. ${ }^{14}$ A successful denture base must have adequate mechanical properties for patient satisfaction. ${ }^{3}$ Flexural stress during mastication can break the denture base. Moreover, a gradual irregular pattern of bone resorption can make the denture base become supported by uneven alveolar ridges. ${ }^{15}$ Furthermore, low impacts and decreased flexural strength of the PMMA denture base material may cause a denture fracture. ${ }^{16}$ Thus, high machinal properties, like flexural strength, of the denture base material is mandatory in preventing denture fractures under masticatory loading. The modulus of elasticity plays an important role in material rigidity, with an increase in the value, there is a decrease in elastic deformation and thus greater rigidity of the material. ${ }^{17}$ To prevent permanent deformation of denture base materials caused by continuous stress or strain during mastication, these materials should have a high level of elastic modulus. ${ }^{18}$

Although previous studies have been done on nano- $\mathrm{SiO}_{2}$, the flexural properties of denture base materials modified with low levels of nano- $\mathrm{SiO}_{2}$ have not been investigated. Therefore, this study was done to evaluate the flexural strength and elastic modulus of PMMA denture bases following the addition of low concentrations of nano-SiO ${ }_{2}$. The null hypothesis of the study was that the incorporation of low concentrations of nano- $\mathrm{SiO}_{2}$ would not improve the flexural strength of the PMMA-modified denture base resin.

\section{Materials and Methods}

The morphology and structure of the nano-SiO 2 (AEROSIL R812; Evonik Degussa, Germany) were analyzed first by using a scanning electron microscope (SEM; Inspect S50; FEI, Brno, Czech Republic) and a transmission electron microscope (TEM; Morgagni 268; FEI, Brno, Czech Republic). The SEM and TEM were operated at an accelerated voltage of $20 \mathrm{kV}(80 \mathrm{kV})$, respectively. The SEM and TEM analyses showed the characteristics and specifications of the nanoparticles (-Fig. 1). The nano- $\mathrm{SiO}_{2}$ particles exhibited spherical shapes with some degree of aggregation. Using the TEM, the average size
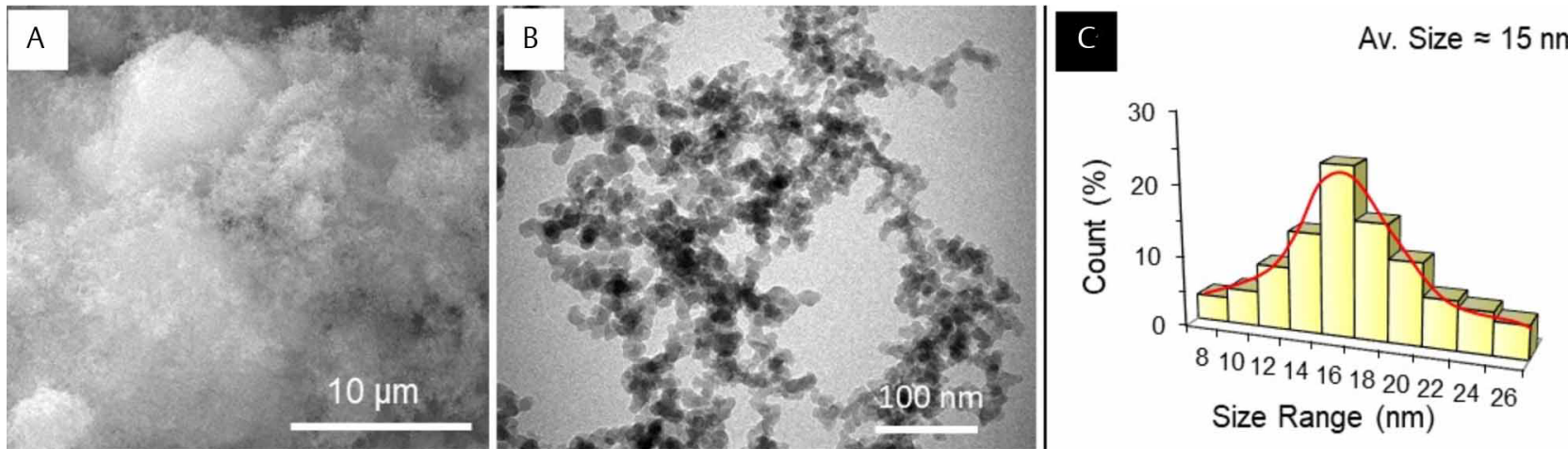

Fig. 1 Representative (A) Scanning and (B) transmission electron microscopy and (C) size histogram of the nano-SiO ${ }_{2}$ particles. The nano- $\mathrm{SiO}_{2}$ particles were spherical in shape with an average size of approximately $15 \mathrm{~nm}$. nano-SiO ${ }_{2}$, silicon dioxide nanoparticles. 
of the particles was calculated at around $15 \mathrm{~nm}$. Nano-SiO (white color; 99.5\% purity; average size: $15 \mathrm{~nm}$; specific surface area: $150-550 \mathrm{~m}^{2} / \mathrm{g}$; and density: $2.2 \mathrm{~g} / \mathrm{cm}^{3}$ ) were then silanized with 3-(trimethoxysilyl) propyl methacrylate, (97\%; $\gamma$-MPS) and silane (Shanghai Richem International, Shanghai, China) following the steps described by Karci et al and da Silva et al. ${ }^{19,20}$ The silanized nano-SiO ${ }_{2}$ was weighed with a digital balance (WENSAR Mab Dab Series Analytical Balance, DAB 220) in concentrations of $0.05,0.25,0.5$, and $1.0 \mathrm{wt} \%$ of the heat-polymerized acrylic powder ${ }^{19,20}$ (Major Base 20; Major Prodotti Dentari SPA, Moncalieri, Italy). The concentrations of nano- $\mathrm{SiO}_{2}$ were independently blended with the PMMA powder at $400 \mathrm{rpm}$ for 30 minutes to ensure equal filler distribution within the PMMA powder. Before heat polymerization, the mixture (PMMA/nano- $\mathrm{SiO}_{2}$ ) was evaluated by using the SEM to verify the uniform distribution of the nanoparticles within the PMMA powder ( - Fig. 2). For comparison, the powder of the pure PMMA specimen was analyzed, which also measured the average diameter of the PMMA spheres at approximately $25 \mu \mathrm{m}$.

A total of 50 rectangular acrylic specimens with dimensions of $65 \times 10 \times 2.5 \mathrm{~mm}^{3}$ were fabricated from heat-polymerized acrylic resin. In accordance with the amount of nano- $\mathrm{SiO}_{2}$, specimens were divided into five groups ( $n=10$ per group), a control group (with no additional nano- $\mathrm{SiO}_{2}$ ) and four study groups modified with $0.05,0.25,0.5$, and $1.0 \mathrm{wt} \%$ nano- $\mathrm{SiO}_{2}$ of acrylic powder. Flexural strength and elastic modulus were measured by using a 3-point bending test with a universal testing machine. A SEM was used for fracture surface analysis. Data analyses were conducted through analysis of variance (ANOVA) and Tukey's post hoc tests $(\alpha=0.05)$. Acrylic resin specimens were prepared in a conventional method for denture base fabrication as described by Alzayyat et al. ${ }^{14}$ Polishing was performed by using progressively finer, cylindrical silicon polishers (FINOPOL Polishers, 64830;
LABOSHOP GmbH, Germany). To standardize the polishing procedure, it was performed by one investigator using a polishing cloth disk (TexMet C10 in, 42-3210, Buehler GmbH, Dusseldorf, Germany) and a mechanical polisher (Metaserve 250 grinder polisher; Buehler) at $100 \mathrm{rpm}$ for 5 minutes in a wet environment. Specimens were stored in distilled water at $37^{\circ} \mathrm{C}$ for 48 hours prior to testing.

Flexural strength was measured by using a 3-point bending test on a universal testing machine (Electropuls E3000, Instron, United Kingdom). Each specimen was placed on the 3-point flexure apparatus where the support span was $50 \mathrm{~mm}$. A load was applied at the midpoint of the prepared area with a crosshead speed of $5 \mathrm{~mm} / \mathrm{min}$ until the specimen fractured, which is when the fracture load was recorded. The following formula was used to calculate the flexure strength values $^{21}$ :

\section{$\mathrm{FS}=3 \mathrm{WL} / 2 \mathrm{bh}^{2}$}

Where FS is the flexural strength (MPa), $\mathrm{W}$ is the fracture $\operatorname{load}(\mathrm{N}), \mathrm{L}$ is the distance between the two supports, $\mathrm{b}$ is the specimen width, and $\mathrm{h}$ is the specimen thickness.

The elastic modulus was calculated by using the results from the flexural strength test using the following formula $\mathrm{a}^{22}$ :

$$
\mathrm{E}=\mathrm{FL}^{3} / 4 \mathrm{bh}^{3} \mathrm{~d}
$$

Where $\mathrm{E}$ is the elastic modulus (MPa), $\mathrm{F}$ is the $\operatorname{load}(\mathrm{N})$ at a convenient point (p) in the straight line of the tension/deformation curve (elastic deformation), $\mathrm{L}$ is the distance between the two supports, $\mathrm{b}$ is the specimen width, $\mathrm{h}$ is the specimen thickness, and $d$ is the deflection at point $\mathrm{p}$.

After the flexural tests, the surface morphologies of the fractured specimens were analyzed by using the SEM. The SEM was operated at a medium accelerating voltage of $20.0 \mathrm{kV}$. For better image acquisition, the charging effects were minimized by coating the specimens with gold using

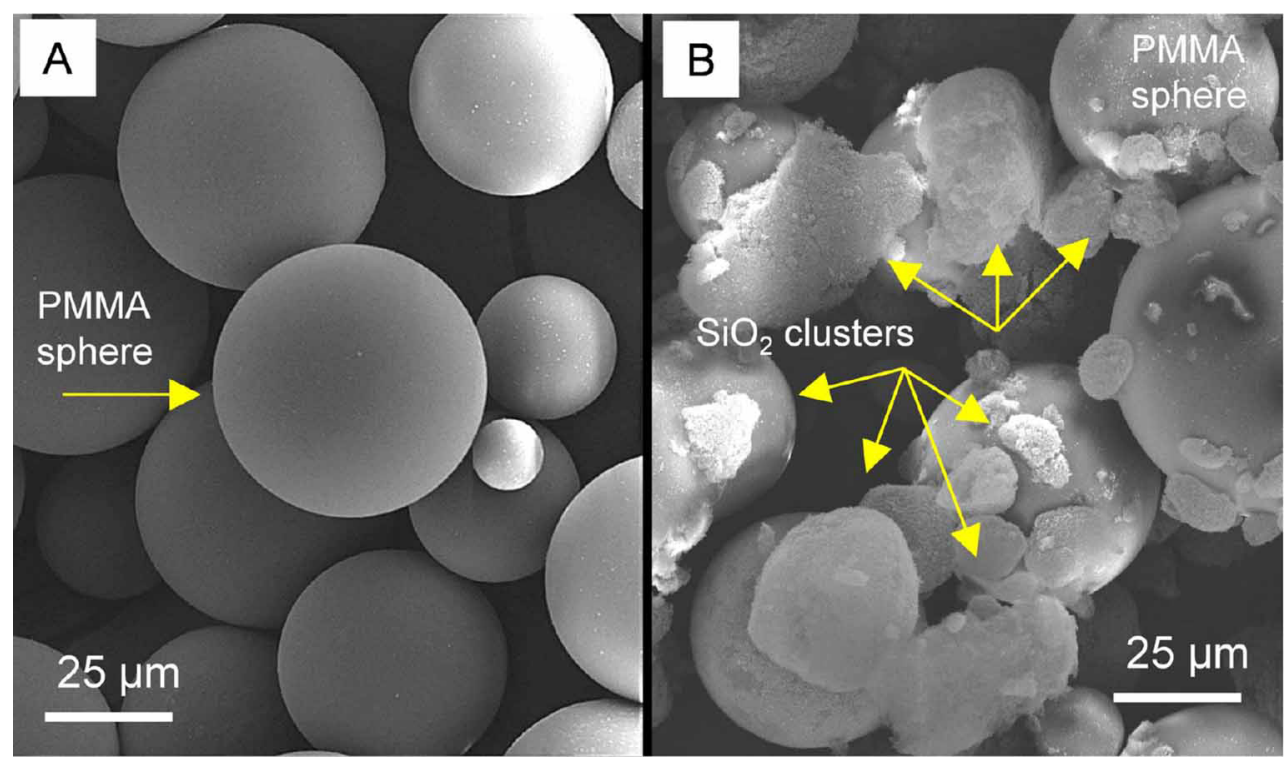

Fig. 2 Scanning electron microscopy micrographs of the $(\mathbf{A})$ pure PMMA and (B) a PMMA/nano-SiO 2 mixture at the same magnification. A PMMA sphere and the clusters of nano-SiO, particles are highlighted with arrows. The scale bars are $25 \mu \mathrm{m}$. PMMA, polymethylmethacrylate. nano-SiO , silicon dioxide nanoparticles. 
a sputter coating machine (Quorum, Q150R ES, United Kingdom). The SEM micrographs of the control PMMA and $\mathrm{PMMA} / \mathrm{SiO}_{2} / \mathrm{PMMA}$ nanocomposite specimens were obtained at different magnifications to capture the important surface features and determine the mode of failure. The cross-sectional images of both the control and composite specimens are displayed at a representative magnification of $\times 1,000$ ( - Fig. 3 ). For a better comparison between different specimens, the electronic micrographs are shown at the same magnification.

The Statistical Package for Social Sciences (SPSS version 23) was used for data analysis. In the descriptive analyses, the means and standard deviations were calculated for each group. For inferential statistics, the normality of the data was tested first. Insignificant $p$-values from the Shapiro-Wilk test revealed that the data were normally distributed. Hence, a one-way ANOVA was used to test for any significance differences in mean values for flexural strength and elastic modulus at different concentration levels. In case of a significant ANOVA result, Tukey's post hoc test was used for a pairwise comparison. The $p$-values less than 0.05 were considered statistically significant.

\section{Results}

The variations for different nano- $\mathrm{SiO}_{2}$ concentrations on flexure strength and modulus of elasticity are presented in - Table 1. ANOVA results revealed that the variations in the mean elastic modulus and flexural strength due to changes in
nano-SiO ${ }_{2}$ concentrations were significant. After performing statistical significance tests for flexure strength and elastic modulus, pairwise comparisons between the groups were tested through Tukey's post hoc tests. The means, standard deviations, and significance levels of flexure strength and elastic modulus for varying nano- $\mathrm{SiO}_{2}$ concentrations are summarized in - Table 2 . Our results showed that all tested groups had significantly higher flexural strength compared with the control group $(p<0.001)$. As such, the lowest flexural strength was with the control group $(80.7 \pm 1.75 \mathrm{MPa})$. Between the nano- $\mathrm{SiO}_{2}$ groups, there was a significant $(p<$ 0.001 ) decrease in flexural strength, which was concentration dependent. As the concentration of nano-SiO ${ }_{2}$ increased, the flexural strength decreased, and at $1.0 \%$ nano- $\mathrm{SiO}_{2}$ the lowest flexural strength value ( $87.6 \pm 1.4 \mathrm{MPa})$ was observed. For the elastic modulus, significantly increased $(p<0.001)$ at $0.05 \%$ with highest value $(9,238.98 \pm 86.1 \mathrm{MPa})$ followed by $1.0,0.25,0.5 \%$, and least in control group. Pairwise comparisons of the elastic modulus between the control group and various concentrations of nano- $\mathrm{SiO}_{2}$ showed a significant increase in elastic modulus compared with the control group $(p<0.001)$. Between the nano- $\mathrm{SiO}_{2}$ groups, the $0.05 \%$ group had the highest elastic modulus value $(9,238.98 \pm 86.1 \mathrm{MPa})$. Pairwise comparisons between the group means found significant differences between all groups, with the exception of a nonsignificant difference between the $0.25 \%$ nano- $\mathrm{SiO}_{2}$ and $0.5 \%$ nano- $^{-S_{O}}{ }_{2}(p=0.121)$ groups. The highest elastic modulus was recorded with $0.05 \%(9,238.98 \pm 86.1 \mathrm{MPa})$ followed by $1.0 \%$ nano- $\mathrm{SiO}_{2}(8,768.1 \pm 96.0 \mathrm{MPa})$, while the
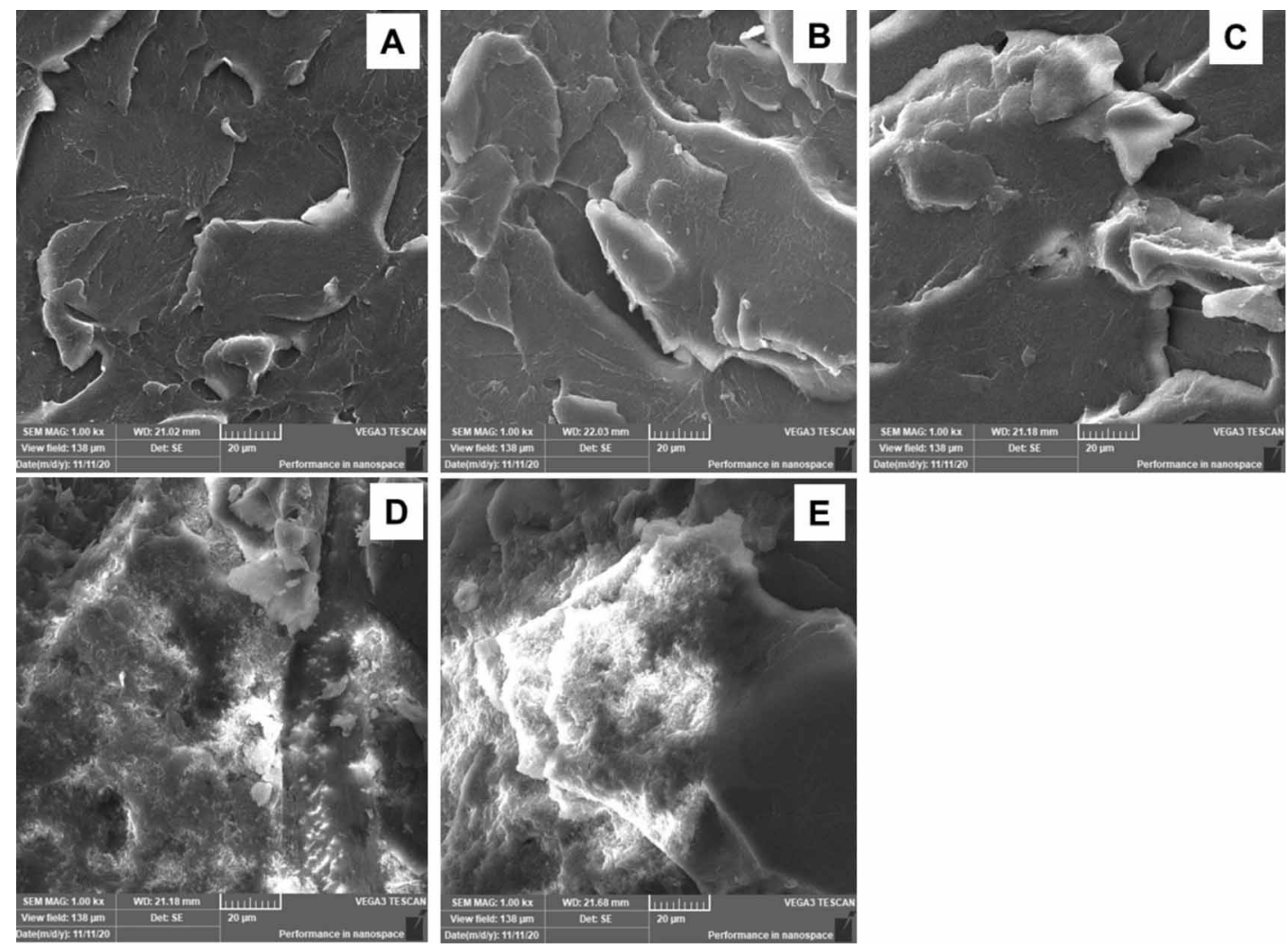

Fig. 3 Representative scanning electron microscopy images of fractured specimens (A) unmodified, (B) $0.05 \% \mathrm{SiO}_{2}$, (C) $0.25 \% \mathrm{SiO}_{2}$, (D) $0.5 \%$ $\mathrm{SiO}_{2}$, and $(\mathbf{E}) 1.0 \% \mathrm{SiO}_{2}$. nano- $\mathrm{SiO}_{2}$, silicon dioxide nanoparticles. 
Table 1 Analysis of variance analysis of tested properties

\begin{tabular}{|l|l|l|l|l|l|l|}
\hline \multirow{3}{*}{ Flexural strength } & Groups & Sum of squares & df & Mean square & F-value & $p$-Value \\
\cline { 2 - 8 } & Between groups & 2194.489 & 4 & 548.622 & 220.622 & $0.000^{\text {a }}$ \\
\cline { 2 - 8 } & Within groups & 111.902 & 45 & 2.487 & & \\
\cline { 2 - 7 } & Total & 2306.391 & 49 & & & \\
\hline \multirow{5}{*}{ Elastic modulus } & Between groups & 41623604.984 & 4 & 10405901.246 & 1783.008 & $0.000^{\text {a }}$ \\
\cline { 2 - 8 } & Within groups & 262626.781 & 45 & 5836.151 & & \\
\cline { 2 - 7 } & Total & 41886231.77 & 49 & & & \\
\hline
\end{tabular}

aStatistically significant at 0.05 level of significance.

Table 2 Mean values, standard deviations, and significance levels between tested groups in relation to silicon dioxide nanoparticles concentrations

\begin{tabular}{|l|l|l|}
\hline Groups & $\begin{array}{l}\text { Flexural strength } \\
\text { (MPa) } \\
\text { Mean (SD) }\end{array}$ & $\begin{array}{l}\text { Elastic modulus } \\
\text { (MPa) } \\
\text { Mean (SD) }\end{array}$ \\
\hline Control & $80.7(1.75)$ & $6540.1(57.3)$ \\
\hline $0.05 \%$ & $98.9(1.77)$ & $9238.98(86.1)$ \\
\hline $0.25 \%$ & $96.7(1.43)$ & $8268.7(66.9)^{\mathrm{a}}$ \\
\hline $0.5 \%$ & $93.7(1.5)$ & $8184.9(69.2)^{\mathrm{a}}$ \\
\hline $1.0 \%$ & $87.6(1.4)$ & $8768.1(96.0)$ \\
\hline
\end{tabular}

Abbreviation: SD, standard deviation.

${ }^{a}$ Nonsignificance between groups $(p>0.05)$.

lowest values were recorded with $0.5 \%$ nano- $\mathrm{SiO}_{2}$ and $0.25 \%$ nano- $\mathrm{SiO}_{2}$ with values of $8,184.9 \pm 69.2 \mathrm{MPa}$ and $8,268.7$ $\pm 66.9 \mathrm{MPa}$, respectively, without a significant difference between these.

The representative SEM micrographs of the fractured unmodified and modified PMMA specimens (control $=0.05$, $0.25,0.5$, and $1 \mathrm{wt} \%$ ) are displayed in - Fig. 1. We observed that the surface morphology of the reinforced groups was greatly altered after the inclusion of nano- $\mathrm{SiO}_{2}$ into the PMMA matrices. These alterations seemed to be related to the increasing filler concentrations compared with the control group. As shown in - Fig. 1, the control specimen displayed a uniform lamellar structure with an absence of voids (-Fig. 1A). Alternatively, the modified specimens $(0.05,0.25$, 0.5 , and $1 \mathrm{wt} \% \mathrm{SiO}_{2}$ ) had some voids and nano-SiO${ }_{2}$ particles in the form of clusters or agglomerations. The number of cluster particles and the size of the clusters increased with the increase in nano- $\mathrm{SiO}_{2}$ concentration in the PMMA matrix. Large aggregations of nano- $\mathrm{SiO}_{2}$ particles were clearly seen with the two groups containing 0.5 and $1.0 \%$ of $\mathrm{SiO}_{2}$ (-Figs. 3D and E ). The lamellar structure that appeared in the 0.05 and $0.25 \%$ specimens looked similar to the control group. However, this changed slightly to a faint lamella for the $0.5 \%$ group and finished with a smooth background in the $1.0 \% \mathrm{SiO}_{2}$ group. The appearance of a whitened contrast due to the nature of the nano- $\mathrm{SiO}_{2}$ (poor electrical conductivity) reflected a brittle fracture. The composite matrix layer around the nano- $\mathrm{SiO}_{2}$ particles became stress whitened for low concentrations of nano- $\mathrm{SiO}_{2}$ (- Figs. 3B and C). This suggests that with the addition of low concentrations of nano- $\mathrm{SiO}_{2}$, the PMMA matrix yielded to produce plastic deformation, which absorbed deformation energy to improve the flexural strength of the modified specimens. For the 0.5 and $1.0 \mathrm{wt} \% \mathrm{SiO}_{2}$, the modified PMMA fractured surface ( - Figs. 3D and E) showed that with an increased filler ratio, there was a decreased adhesion between the PMMA matrix and the nano- $\mathrm{SiO}_{2}$ particles, which resulted in a drop in strength.

\section{Discussion}

This study evaluated the effects of the addition of low concentrations of nano- $\mathrm{SiO}_{2}$ on the flexural strength and elastic modulus of a final PMMA/SiO ${ }_{2}$ nanocomposite. Based on the results, both the elastic modulus and flexural strength were affected by nano- $\mathrm{SiO}_{2}$ additions. Therefore, the null hypothesis was rejected.

The results showed significant increases in flexural strength in comparison to the unmodified group. This finding agreed with Gad et $\mathrm{al}^{12}{ }^{12}$ who found that the addition of nano- $\mathrm{SiO}_{2}$ in low concentrations significantly improved the flexural strength of repaired acrylic resins. The increase in flexural strength may be attributed to the homogeneous distribution of low concentrations of $\mathrm{SiO}_{2}$. In addition, it has been suggested that its surface design fills the interpolymeric chain space of the resin base and restricts their movement, which can increase the flexural strength. ${ }^{12}$ Moreover, the silane enables nano- $\mathrm{SiO}_{2}$ to form strong bonds with the polymer matrix creating crosslink bonds that may inhibit the crack progression and increase the flexure strength..$^{23}$ Alternatively, the results of Mussatto et al found that loaded nano- $\mathrm{SiO}_{2}$ into a resin denture base reduces the flexural strength. However, this was not concentration dependent nor affected by the method used. No major differences have been observed with surface silanization in mechanical behavior. ${ }^{24}$

Among the nano- $\mathrm{SiO}_{2}$ groups, there was a concentration-dependent decrease in flexural strength with higher concentrations of nano- $\mathrm{SiO}_{2}$. This reduction can be explained by the agglomeration of nano- $\mathrm{SiO}_{2}$, which helps in the formation of loosely attached clusters acting as a stress-concentrating center that subsequently decreases the flexural strength. ${ }^{1,23}$ Also, the presence of voids may be responsible for decreasing the flexural strength, thus leading to fractures of the resin base due to these voids. ${ }^{11,12}$ Karci et $\mathrm{al}^{19}$ have investigated PMMA incorporated with various 
concentrations of nano- $\mathrm{SiO}_{2}(1.0,3$, and $5 \%)$ and found that the flexural strength increases with $1.0 \%$ in comparison with the control group, but decreased as nano- $\mathrm{SiO}_{2}$ concentrations increased further. The greatest decrease was at $5 \%$ nano- $\mathrm{SiO}_{2}$, which corresponds with our results where the greatest decrease was at $1.0 \%$ nano- $\mathrm{SiO}_{2}$, which was the highest concentration used in the present study. ${ }^{19}$ Moreover, findings by Cevik and Yildirim-Bicer agree with this study's results. This group reported that adding nano- $\mathrm{SiO}_{2}$ in higher concentrations reduces flexural strength in the 1.0 and $5 \%$ groups. These decreases are thought to be due to voids and porosity changes, as shown with SEM findings in silica-incorporated specimens, which result in a reduced flexural strength. ${ }^{11}$

The mechanical properties of the final PMMA/SiO ${ }_{2}$ nanocomposite depends on the shape, size, concentrations, and interactions with the polymer matrix. ${ }^{25}$ It has been reported that nano- $\mathrm{SiO}_{2}$ have the lowest density, and this results in an increased particle amount per unit area compared with other metal oxide $\left(\mathrm{Al}_{2} \mathrm{O}_{3}\right.$ and $\left.\mathrm{TiO}_{2}\right)$ nanoparticles of the same concentration. This suggests that more agglomerations on the surface of the specimens lower the mechanical properties in nano- $\mathrm{SiO}_{2}$ reinforced groups. ${ }^{19}$ For example, higher concentrations of nano- $\mathrm{SiO}_{2}(5 \%)$ indicate a higher volume and lower density of nano- $\mathrm{SiO}_{2}$ in the matrix with more agglomeration. Therefore, lower concentrations of nano- $\mathrm{SiO}_{2}$ are recommended. ${ }^{19}$

Maxillary dentures frequently have midline fractures due to continuous flexion of the denture. Thus, the denture base should have satisfactory elastic modulus and flexural strength properties to avoid fractures and permanent deformations. ${ }^{26,27}$ According to the results of the present study, the elastic modulus increased at $0.05 \%$ compared with the control group and decreased at 0.25 and $0.5 \%$. However, the obtained elastic modulus values were still above the minimum recommended values (2,000 $\mathrm{MPa}$ ) set by the American Dental Association specifications. ${ }^{28,29}$

At $1.0 \%$ nano- $\mathrm{SiO}_{2}$, the elastic modulus increased, and this increase may have been due to zeta sizer results, the micron distance between the nanoparticles, which can considerably reduce the polymer chain immobilization effect. ${ }^{30}$ In addition, a relatively large agglomeration forms if the distribution of nanoparticles is not optimal, which leads to areas of material without reinforced nanoparticles without an immobilization effect. Therefore, there is a possibility of crack propagation between the reinforced fields through the unreinforced material. This agrees with Balos et al who used different concentrations of nano-SiO${ }_{2}$. This group found that with higher concentrations of nanoparticles and better particle distribution with $2 \%$ nanoparticles, there is a higher elastic modulus compared with $1.5 \%$ nanoparticles, which may be due to a less convenient zeta potential. ${ }^{30}$

Clinically, the PMMA/SiO 2 nanocomposite in a low concentration $(0.05 \%)$ is promising for the denture base in terms of increasing flexural strength and the elastic modulus. However, the durability of this nanocomposite with the effects of various aging procedures (immersion in water, denture cleanser, brushing, and thermal stressing) requires more investigations. One limitation of this study was testing the mechanical properties of one type of acrylic resin in specimens that did not resemble a complete denture configuration or the environment of the oral cavity in addition to the low sample size. Accordingly, it is recommended to study nanocomposites containing low concentrations of nano- $\mathrm{SiO}_{2}$ and different denture base resin materials with artificial aging factors on complete denture bases in conditions simulating the oral cavity.

\section{Conclusion}

Within the limitations of this study, we conclude that the incorporation of low concentrations of nano- $\mathrm{SiO}_{2}$ into a PMMA denture base resin increased the flexural strength, and this increase was concentration dependent. A low concentration of nano- $\mathrm{SiO}_{2}(0.05 \%)$ is the preferable concentration that may increase the flexural and elastic modulus properties of modified denture base resins.

\section{Funding \\ None.}

\section{Conflict of Interest}

None declared.

\section{References}

1 Peyton FA. History of resins in dentistry. Dent Clin North Am 1975;19(2):211-222

2 Gad MM, Fouda SM, ArRejaie AS, Al-Thobity AM. Comparative effect of different polymerization techniques on the flexural and surface properties of acrylic denture bases. J Prosthodont 2019;28(4):458-465

3 Jagger DC, Harrison A, Jandt KD. The reinforcement of dentures. J Oral Rehabil 1999;26(3):185-194

4 Azzarri MJ, Cortizo MS, Alessandrini JL. Effect of the curing conditions on the properties of an acrylic denture base resin microwave-polymerised. J Dent 2003;31(7):463-468

5 Gad MM, Fouda SM, Al-Harbi FA, Näpänkangas R, Raustia A. PMMA denture base material enhancement: a review of fiber, filler, and nanofiller addition. Int J Nanomedicine 2017;12:3801-3812

6 Vikram S, Chander NG. Effect of zinc oxide nanoparticles on the flexural strength of polymethylmethacrylate denture base resin. Eur Oral Res 2020;54(1):31-35

7 Vojdani M, Bagheri R, Khaledi A. Effects of aluminum oxide addition on the flexural strength, surface hardness, and roughness of heat-polymerized acrylic resin. J Dent Sci 2012;7(3):238-244

8 Sodagar A, Khalil S, Kassaee MZ, Shahroudi AS, Pourakbari B, Bahador A. Antimicrobial properties of poly (methyl methacrylate) acrylic resins incorporated with silicon dioxide and titanium dioxide nanoparticles on cariogenic bacteria. J Orthod Sci 2016;5(1):7-13

9 Sodagar A, Bahador A, Khalil S, Shahroudi AS, Kassaee MZ. The effect of $\mathrm{TiO} 2$ and $\mathrm{SiO} 2$ nanoparticles on flexural strength of poly (methyl methacrylate) acrylic resins. J Prosthodont Res 2013;57(1):15-19

10 Mahross HZ, Baroudi K. Effect of silver nanoparticles incorporation on viscoelastic properties of acrylic resin denture base material. Eur J Dent 2015;9(2):207-212 
11 Cevik P, Yildirim-Bicer AZ. The effect of silica and prepolymer nanoparticles on the mechanical properties of denture base acrylic resin. J Prosthodont 2018;27(8):763-770

12 Gad MM, Abualsaud R, Al-Thobity AM, et al. Effect of $\mathrm{SiO} 2$ nanoparticles addition on the flexural strength of repaired acrylic denture base. Eur J Dent 2020;14(1):19-23

13 Abushowmi TH, AlZaher ZA, Almaskin DF, et al. Comparative effect of glass fiber and nano-filler addition on denture repair strength. J Prosthodont 2020;29(3):261-268

14 Alzayyat ST, Almutiri GA, Aljandan JK, et al. Antifungal efficacy and physical properties of poly(methylmethacrylate) denture base material reinforced with $\mathrm{SiO} 2$ nanoparticles. J Prosthodont 2021;30(6):500-508. Doi:10.1111/jopr.13271

15 Diaz-Arnold AM, Vargas MA, Shaull KL, Laffoon JE, Qian F. Flexural and fatigue strengths of denture base resin. J Prosthet Dent 2008;100(1):47-51

16 Ozkir SE, Yilmaz B, Unal SM, Culhaoglu A, Kurkcuoglu I. Effect of heat polymerization conditions and microwave on the flexural strength of polymethyl methacrylate. Eur J Dent 2018;12(1):116-119

17 McCabe J, Walls A, Applied Dental Materials. 8th ed. Oxford: Blackwell Science; 200897

18 Ajaj-Alkordy NM, Alsaadi MH. Elastic modulus and flexural strength comparisons of high-impact and traditional denture base acrylic resins. Saudi Dent J 2014;26(1):15-18

19 Karci M, Demir N, Yazman S. Evaluation of flexural strength of different denture base materials reinforced with different nanoparticles. J Prosthodont 2019;28(5):572-579

20 da Silva LH, Feitosa SA, Valera MC, de Araujo MA, Tango RN. Effect of the addition of silanated silica on the mechanical properties of microwave heat-cured acrylic resin. Gerodontology 2012;29(2):e1019-e1023
21 Gundogdu M, Yanikoglu N, Bayindir F, Ciftci H. Effect of repair resin type and surface treatment on the repair strength of polyamide denture base resin. Dent Mater J 2015;34(4):485-489

22 International Organization for Standardization, DentistryBase Polymers - Part 1: denture base polymers. Volume 20795-1:2008. Geneva: ISO; 2013

23 Katsikis N, Zahradnik F, Helmschrott A, Münstedt H, Vital A. Thermal stability of poly (methyl methacrylate)/silica nanoand microcomposites as investigated by dynamic-mechanical experiments. Polym Degrad Stabil 2007;92(11):1966-1976

24 Mussatto CMB, Oliveira EMN, Subramani K, Papaléo RM, Mota EG. Effect of silica nanoparticles on mechanical properties of self-cured acrylic resin. J Nanopart Res 2020;22(11):317

25 Jordan J, Jacob K, Tannenbaum R, Sharaf M, Jasiuk I. Experimental trends in polymer nanocomposites-a review. Mater Sci Eng A 2005;393(1-2):1-11

26 Bera O, Pavličević J, Jovičić M, Stoiljković D, Pilić B, Radičević R. The influence of nanosilica on styrene free radical polymerization kinetics. Polym Compos 2011;33(2):262-266

27 Fragiadakis D, Pissis P, Bokobza L. Glass transition and molecular dynamics in poly(dimethylsiloxane)/silica nanocomposites. Polymer 2005;46(16):6001-6008

28 Revised american dental association specification no. 12 for denture base polymers. J Am Dent Assoc 1975;90(2):451-458

29 Cunha TR, Regis RR, Bonatti MR. de Souza RF. Influence of incorporation of fluoroalkyl methacrylates on roughness and flexural strength of a denture base acrylic resin. J Appl Oral Sci 2009;17(2):103-107

30 Balos S, Puskar T, Potran M, et al. Modulus, strength and cytotoxicity of PMMA-silica nanocomposites. Coatings 2020;10(6):583 